\title{
Direct cyclopexy surgery for post-traumatic cyclodialysis with persistent hypotony: ultrasound biomicroscopic evaluation
}

\author{
Ciclopexia direta em ciclodiálise pós-traumática com hipotonia ocular persistente - \\ acompanhamento por biomicroscopia ultrassônica (UBM)
}

Fabiola Murta ${ }^{1}$, Somaia Mitne ${ }^{1,2}$, Norma Allemann², Augusto Paranhos Junior 3

\begin{abstract}
Cyclodialysis is a relatively rare condition usually caused by ocular injury; however, it can also be caused iatrogenically during intraocular surgery. Hypotony maculopathy is the most important complication and the primary reason for visual loss. Clinical diagnosis using gonioscopy may be difficult, and ultrasound biomicroscopy (UBM) can be an alternative. There are different kinds of treatments, and the optimal one remains controversial. Here we describe a case of traumatic cyclodialysis with persistent ocular hypotony treated by direct cyclopexy, as illustrated by UBM performed before and after surgery.
\end{abstract}

Keywords: Refractive errors/surgery; Eye injuries/complications; Eye injuries/ ultrasonography; Ocular hypotension/etiology; Ciliary body/injuries; Gonioscopy; Tomography, optical coherence/methods; Microscopy/methods; Visual acuity; Case reports; Humans; Male; Adult

\section{RESUMO}

Ciclodiáliseéuma condição relativamenterara, geralmente devido a um trauma ocular, mas também pode ser causada iatrogenicamente como consequência de cirurgia intraocular. A maculopatia hipotônica éa complicação mais importante e a principal razão para a perda visual nessa situação. O diagnóstico clínico por gonioscopia pode ser difícil e a biomicroscopia ultrassônica (UBM) pode ser uma alternativa. Existem diferentes tipos de tratamentos e algumas controvérsias sobre a melhor opção. Neste relato, nós descrevemos um caso de ciclodiálise traumática com hipotonia ocular persistente tratado por cyclopexia direta avaliado por UBM antes e depois da cirurgia.

Descritores: Erros de refração/cirurgia; Lesão nos olhos/complicações; Lesão nos olhos/ultrassonografia; Hipotensão ocular/etiologia; Corpo ciliar/lesões; Gonioscopia; Tomografia de coerência óptica/métodos; Microscopia/métodos; Acuidade visual; Relato de caso; Humanos; Masculino; Adulto

\section{INTRODUCTION}

Cyclodialysis clefts are areas of disinsertion of the meridional ciliary muscle fibers from their attachment at the scleral spur, allowing direct communication between the anterior chamber and the ciliochoroidal space. Previously, cyclodialysis was intentionally caused during an obsolete surgical technique for treating glaucoma ${ }^{(1,2)}$. Nowadays, it is mainly caused by severe blunt ocular trauma ${ }^{(3,4)}$, which causes momentary axial compression and a rapid compensatory equatorial expansion that stretches the ocular tissue, resulting in separation and tearing of the tissue. Intraocular surgeries that manipulate the iris were also reported to be important causes of iatrogenic cyclodialysis ${ }^{(1,3,5)}$, which became less common with the development of better intraocular surgical techniques.

Cyclodialysis is a rare condition ${ }^{(3,6)}$ and results in a shallow anterior chamber, ciliochoroidal detachment, ocular hypotony, and hypotony maculopathy with loss of vision ${ }^{(5,7,8)}$.

Gonioscopy is the best way to examine the structures of the angle $e^{(9)}$, but in some eyes with shallow anterior chambers, hyphema, and corneal opacity, a cyclodialysis cleft may not be visible on clinical examination ${ }^{(3,4,6)}$. To diagnose these clefts and evaluate the location and extent of the cyclodialysis and suprachoroidal effusion, ultrasound biomicroscopy (UBM) is of particular importance $(3,5,7,10)$.
Several modalities for surgical and nonsurgical treatment of hypotony maculopathy have been proposed ${ }^{(6)}$ : medical treatment ${ }^{(10)}$ (long-acting cycloplegic agents such as 1\% atropine sulfate), argon laser cleft photocoagulation, ciliochoroidal diathermy, anterior scleral buckle, transscleral Nd:YAG laser cyclophotocoagulation, transscleral diode laser therapy, direct cyclopexy ${ }^{(1,11)}$, vitrectomy, transscleral cryotherapy with or without gas endotamponade, endoscopic surgery, indirect cyclopexy, and other surgical techniques. The best treatment for these cases remains controversial, although recent publications show better results with direct cyclopexy surgery ${ }^{(4)}$.

Here we present a case of traumatic cyclodialysis not identified by gonioscopy and associated with hypotony maculopathy, which was evaluated by UBM before and after direct cyclopexy surgery.

\section{CASE REPORT}

A 41-year-old male Caucasian presented with a complaint of progressive blurred vision in his left eye after suffering blunt ocular trauma 2 months back.

At the time of presentation, he was undergoing medical treatment for hypotony (cycloplegic and steroid drops), and his Snellen best-corrected visual acuity (BCVA) was 20/20 in the right eye (OD) and counting fingers in the left eye (OS). Slit-lamp examination 
revealed a normal right eye and inferior corectopia; a hemorrhagic, prolapsed vitreous body into the anterior chamber; phacodonesis; iridodonesis; and mild cataract in the left eye. The intraocular pressure (IOP) was $18 \mathrm{mmHg}$ in OD and $0 \mathrm{mmHg}$ in OS. Gonioscopy of OS revealed inferior angle recession. Fundus examination revealed optic disc edema, chorioretinal folds radiating around the macula, tortuosity and dilatation of the retinal vessels (Figure 1A), and a nasal choroidal rupture.

B-scan, 10-MHz ultrasonography revealed superior peripheral choroidal detachment (10 o'clock to 2 o'clock position), an attached retina, optic disc edema, and choroidal thickening (Figure 1B). UBM (50-MHz immersion technique) revealed an anterior chamber depth of $3.0 \mathrm{~mm}$, vitreous herniation into the anterior chamber (Figure 2A), inferior corectopia, apposition of the peripheral iris to the posterior surface of the cornea (Figure 2B), a suspected cyclodialysis cleft at the 7 o'clock position (Figure 2C), and a $360^{\circ}$ ciliary body detachment showing a cavernous pattern of the suprachoroidal space (Figure 2D)

Because of the extensive ciliary body detachment, persistent hypotony with important visual impairment, and the failure of clinical treatment, surgical intervention was indicated. Direct cyclopexy was performed for the 4 quadrants, as described in figures $3 \mathrm{~A}-\mathrm{C}$. Four days after surgery, the BCVA was 20/200, IOP was 14 mmHg, the anterior chamber depth was restored, and fundus examination revealed complete resolution of the retinal folds and no optic disc edema ( $\mathrm{Fi}$ gure 1C), as confirmed by B-scan ultrasound (Figure 1D). On the $14^{\text {th }}$ day, the postoperative IOP increased to $40 \mathrm{mmHg}$ and was controlled with oral acetazolamide, topical apraclonidine, and timolol, following which it decreased to $19 \mathrm{mmHg}$ without medication after 45 days of surgery, when the BCVA was 20/50. At 5 months, the BCVA was 20/40, the IOP was $18 \mathrm{mmHg}$, there was a $+1 /+4$ nuclear cataract, and some residual inferior corectopia with a scar on the scleral flaps sites. There were no signs of maculopathy on ophthalmoscopy. Three years after surgery, the BCVA was 20/50 with a potential acuity meter result of 20/40 and the IOP was $18 \mathrm{mmHg}$. UBM revealed $\mathrm{a}+2 /+4$ nuclear cataract, while gonioscopy revealed a residual cyclodialysis cleft at the 7 o'clock position with residual angle recession. Fundus examination

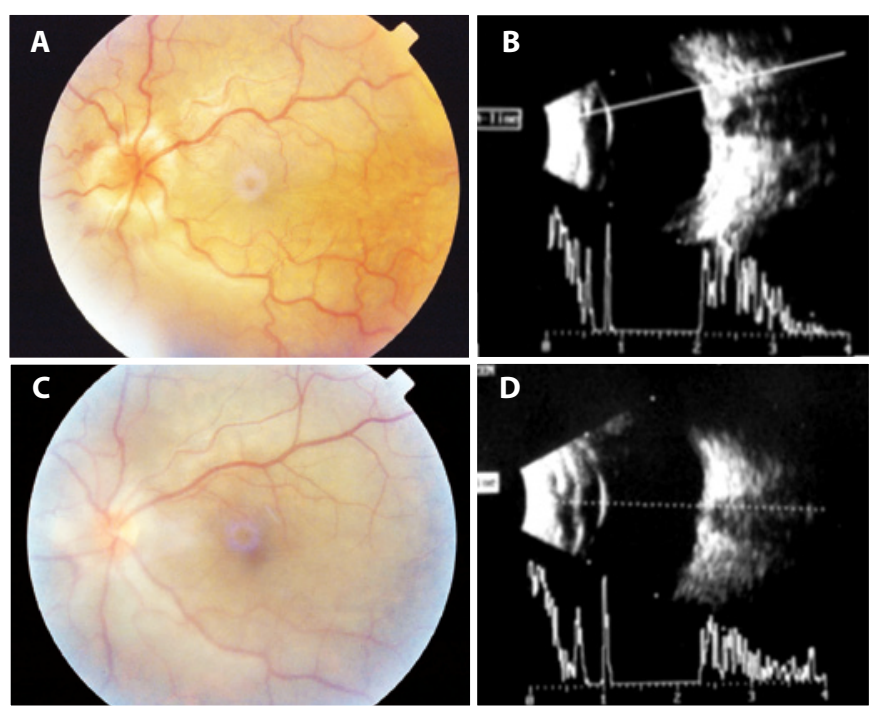

Figure 1. Color images obtained and 10-MHz ultrasound performed before and after surgery. A) A preoperative color image obtained 2 months after blunt ocular trauma shows retinal folds with peripapillary heaping of the disc margins and tortuosity and dilatation of the retinal vessels. B) Preoperative 10-MHz ultrasound performed 2 months after blunt trauma shows optic disc edema and choroidal thickening. C) A color image obtained 4 days after surgery for direct cycloplegy shows total resolution of the retinal folds and heaping of the disc margins. D) $10-\mathrm{MHz}$ ultrasound performed 4 days after direct cyclopexy shows resolution of optic disc edema. showed a discreet pigment irregularity in the macula and a nasal choroidal rupture scar. UBM revealed complete ciliary body attachment, residual inferior corectopia, a residual cyclodialysis cleft inferiorly (from the 5 o'clock position to the 8 o'clock position, probably not observed on gonioscopy because of anterior synechiae), and angle recession at the 9-10 o'clock position (Figures 4A-C).

\section{DISCUSSION}

The term hypotony maculopathy indicates the inward collapse of the scleral wall caused by ocular hypotony. Severe persistent ocular hypotony leads to progressive cataract, chronic inflammation, ciliochoroidal effusion, and hypotony maculopathy with marked vision loss $s^{(1,8)}$. The primary decrease in vision can be related to chorioretinal folds in the macular area, with distortion and malalignment of the retinal photoreceptors. Once the IOP returns to normal, the folds may disappear completely ${ }^{(8)}$. In cases of prolonged hypotony, pigmented lines resulting from changes in the retinal pigment epithelium (RPE) may persist and decrease the final visual acuity ${ }^{(9)}$. Another primary cause of visual decrease in severe hypotony is the decrease in the anteroposterior diameter, which induces relative hyperopia(3)

Hypotony in patients with traumatic ciliary body detachment is caused by a combination of increased uveoscleral outflow via the ciliochoroidal space and a decrease in aqueous production ${ }^{(2,4,5,10)}$, thus decreasing the IOP to levels usually lower than $5 \mathrm{mmHg}$. Although some points on the physiopathology of ocular hypotony caused by cyclodialysis, such as the lack of association between the size of the cleft and the degree of hypotony ${ }^{(2,4,5,9)}$, remain to be clarified, the extent of ciliary body detachment does not seem to be connected to the intensity of hypotony.

UBM is a useful tool for imaging the anterior segment, allowing the visualization of its structures even in the presence of media opacities $^{(4,5,9,10)}$. It can be used as an aid in the diagnosis of cyclodialysis undetectable by gonioscopy ${ }^{(5,11)}$. Although gonioscopy is the gold
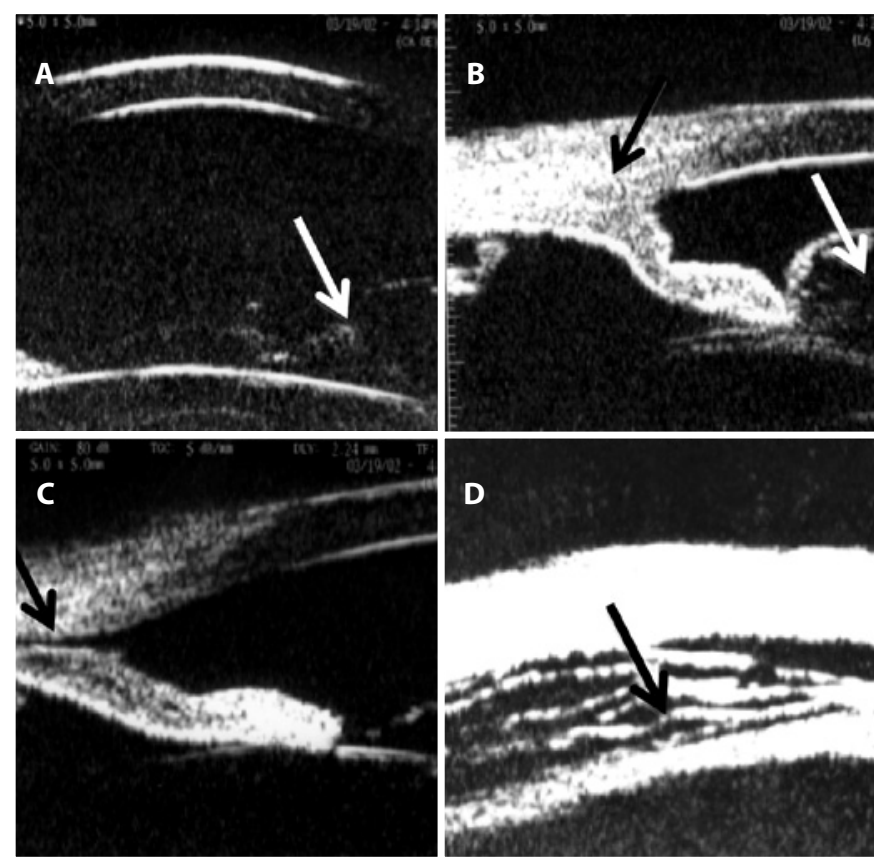

Figure 2. Ultrasound biomicroscopy (UBM) performed at $50 \mathrm{MHz}$ using the immersion technique afterblunt trauma. A) Anterior chamber depth of $3.0 \mathrm{~mm}$, vitreous herniation into the anterior chamber (arrow). B) Inferior angle demonstrating apposition of the peripheral iris (black arrow) to the posterior surface of the cornea associated with vitreous prolapse through the pupil (white arrow). C) A suspected cyclodialysis cleft (black arrow) at the 7 o'clock position. D) Ciliary body detachment (cavernous pattern of the suprachoroidal space; black arrow) in $360^{\circ}$. 
standard for the diagnosis of a cyclodialysis cleft, authors have shown that approximately half of cyclodialysis clefts diagnosed by UBM can be observed on gonioscopy ${ }^{(7)}$. Even in patients with clefts detectable by gonioscopy, UBM is of importance not only to evaluate the dimension and configuration of the supraciliary and choroidal space, giving precise location and extent of the cyclodialysis(5), but also to decide the optimal adequate surgical procedure ${ }^{(5,7)}$, which is considered essential for successful surgery ${ }^{(1)}$ and avoiding excessive surgical invasion. In cases of severe blunt ocular contusion associated with intraocular injuries such as iris sphincter tears, hyphema, and severe hypotony, UBM is crucial because these clinical signs are strongly suggestive of the presence of cyclodialysis clefts ${ }^{(3)}$, which are difficult to detect by gonioscopy because of the softness of the eye and hyphema.

In addition, UBM has been shown to be an important tool for confirming anatomical results after treating cyclodialysis clefts not only by a direct cyclopexy procedure ${ }^{(5,11)}$ but also by any other kind of incisional or nonincisional procedure. Another useful imaging tool for the anterior segment is anterior segment optical coherence tomography $(\mathrm{OCT})$, and in a recent publication, authors have shown that UBM and anterior segment OCT offer similar quality of images of the anterior segment for diagnosing cyclodialysis clefts ${ }^{(12)}$.
Because it is a rare condition, the optimal treatment for traumatic cyclodialysis clefts associated with ocular hypotony and the optimal time for surgical treatment remains controversial ${ }^{(6,9,10)}$. Furthermore, some reports in the literature documented spontaneous closure of cyclodialysis clefts ${ }^{(2)}$ within the first 6 weeks ${ }^{(6)}$. Although there are some doubts about the effectiveness of medical treatment, some studies have proposed that medical treatment should be attempted first, and if hypotony with retinopathy persists, surgical intervention should be considered ${ }^{(11)}$. The Ormerod et al. algorithm ${ }^{(6)}$ is generally followed: 1\% atropine sulfate for cyclodialysis clefts for less than 6 weeks, argon laser photocoagulation if medical treatment is unsuccessful, and direct cyclopexy if laser treatment fails to control the IOP. Some authors prefer cyclocryotherapy over photocoagulation ${ }^{(4)}$. The primary aim of using topical atropine is to induce relaxation of the ciliary muscle, allowing apposition of the detached meridional ciliary muscle to the sclera and aiding in cleft closure; it is usually effective for small clefts. According to Kuchle and Naumann's(1) study, laser photocoagulation can normalize the IOP over the long term only in patients with cyclodialysis clefts smaller than $2 \mathrm{~h}$ of extension. Recent papers favor direct cyclopexy after medical treatment has failed(11) and for moderate to large cyclodialysis clefts. However, a good visual outcome after cyclodialysis repair has been reported even
A

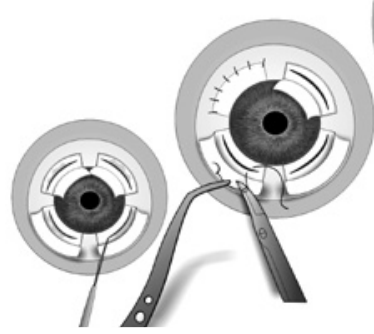

B

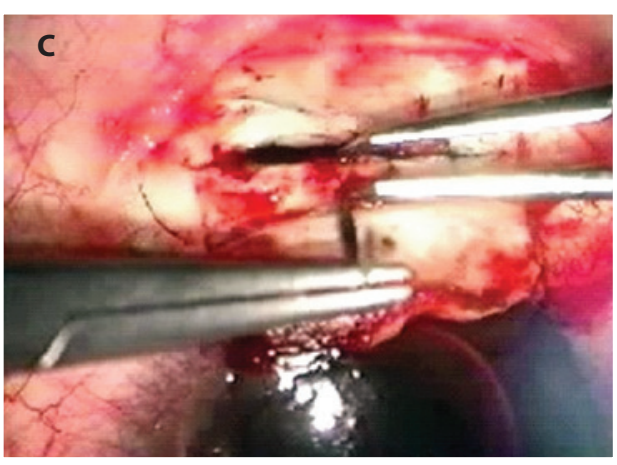

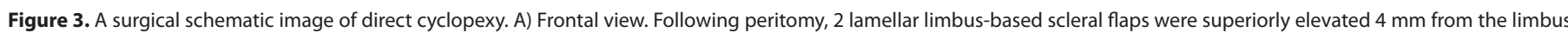

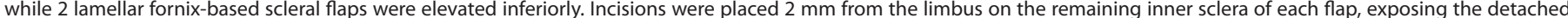

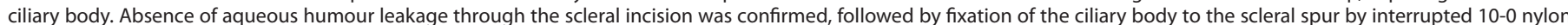

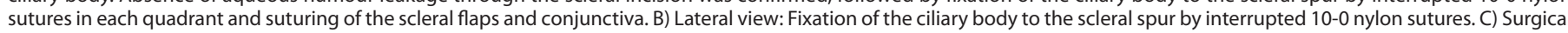

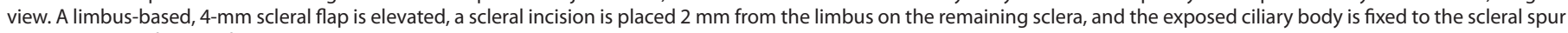
using interrupted 10-0 nylon sutures.
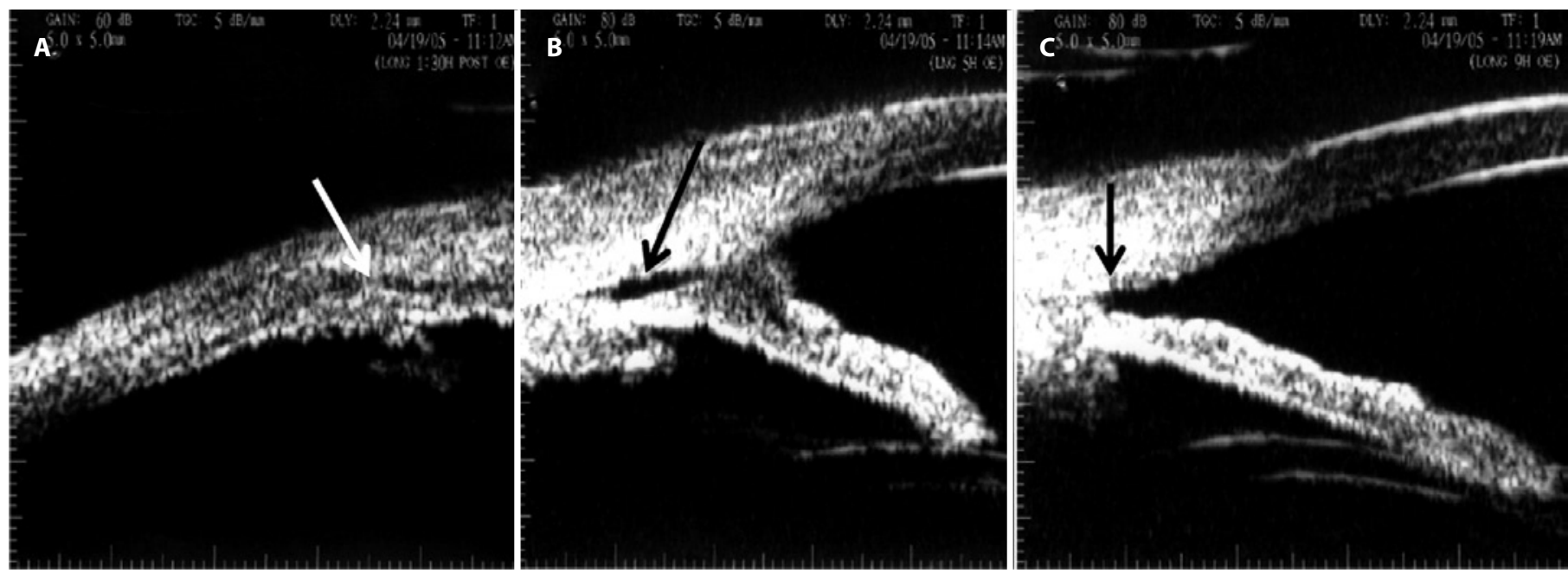

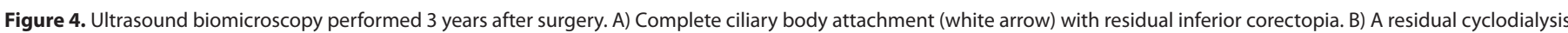
cleft (black arrow) from the 5 o'clock to the 8 o'clock position with adjacent anterior synechiae. C) Angle recession at the 9-10 o'clock position (arrow). 
after several years of severe ocular hypotony $(1,4,6,11)$, and some authors found no correlation between the duration of hypotony and final visual acuity ${ }^{(1,2,4,11)}$. Furthermore, there appears to be no connection between the cleft extent and the final visual outcome; instead, the period required for IOP normalization after direct cyclopexy seems to be correlated to the final visual acuity ${ }^{(11)}$.

Despite this controversy, a majority of authors agree that treatment should not be postponed because of the possibility of permanent vision loss by retinal damage. We believe that while deciding the optimal therapy for cyclodialysis, not only the duration of hypotony but also the extent of cyclodialysis and degree of visual impairment should be taken into account.

Direct cyclopexy is a well-known and effective approach ${ }^{(1,11)}$; it allows the treatment of large areas of cyclodialysis and is an alternative therapy for phakic patients. Direct cyclopexy was the first choice in the present phakic patient because of the large extent of ciliochoroidal detachment, evident hypotony maculopathy, and important visual impairment.

Possible complications of direct cyclopexy include intraocular hemorrhage, endophthalmitis, cataract, vitreous loss, retinal detachment, wound dehiscence, anterior segment ischemia, and secondary glaucoma due to peripheral anterior synechiae. Reversible pressure spikes in the early postoperative course of direct cyclodialysis have been reported after successful closure of the cyclodialysis cleft $\mathrm{f}^{(1,4,8)}$, a condition that can occur in association with other treatment modalities for cyclodialysis ${ }^{(6,9,10)}$, even after spontaneous cleft closure ${ }^{(2)}$. A transient increase in the IOP may assist the resolution of retinal folds and facilitate the adhesion of the ciliary body and sclera ${ }^{(1)}$. Authors have commented that this transient and early IOP spike has no correlation with residual anatomical angle damage ${ }^{(4)}$. Although our patient had a residual cleft after surgery, no clinical effect on the IOP was observed on long-term follow-up, probably because the cleft may have closed at its posterior site. It has been reported that small clefts remaining after treatment do not influence the $\operatorname{IOP}^{(1,2,6)}$.
In conclusion, cyclodialysis can lead to persistent hypotony, thus increasing the possibility of permanent visual loss. Subsidiary examinations such as UBM aids in diagnosis and treatment of cyclodialysis by determining its real dimensions and location, thus guiding the surgeon during surgical repair. In addition, it aids in the evaluation of anatomical surgical success. Cyclopexy can be an effective treatment, particularly in patients with extensive cyclodialysis leading to hypotony maculopathy.

\section{REFERENCES}

1. Kuchle M, Naumann GO. Direct cyclopexy for traumatic cyclodialysis with persisting hypotony. Report in 29 consecutive patients. Ophthalmology. 1995;102(2):322-33. Comment in: Ophthalmology. 1995;102(10):1413.

2. Chandler PA, Maumenee AE. A major cause of hypotony. Am J Ophthalmol. 1961; 52:609-18.

3. Ioannidis AS, Barton K. Cyclodialysis cleft: causes and repair. Curr Opin Ophthalmic. 2010;21(2):150-4.

4. Agrawal P, Shah P. Long-term outcomes following the surgical repair of traumatic cyclodialysis clefts. Eye (Lond). 2013. [Epub ahead of print].

5. Gentile RC, Pavlin CJ, Liebmann JM, Easterbrook M, Tello C, Foster FS, et al. Diagnosis of traumatic cyclodialysis by ultrasound biomicroscopy. Ophthalmic Surg Lasers. 1996; 27(2):97-105.

6. Ormerod LD, Baerveldt G, Sunalp MA, Riekhof FT. Management of the hypotonus cyclodialysis cleft. Ophthalmology. 1991;98(9):1384-93.

7. Roters S, Engels BF, Szurman P, Krieglstein GK. Typical ultrasound biomicroscopic findings seen in ocular hypotony. Ophthalmologica. 2002;216(2):90-5.

8. Demeler U. Surgical management of ocular hypotony. Eye (Lond). 1988;2(Pt 1):77-9.

9. Lopes Filho JG, Costa VP, Goldbaum M. Hipotonia ocular secundária à ciclodiálise: descrição de 4 casos e revisão de literatura. Arq Bras Oftalmol. 1997;60(6):626-30.

10. Kamei C, Kato T, Tsukamoto H, Mishima HK. A case of traumatic cyclodialysis followed by ultrasound biomicroscopy. Hiroshima J Med Sci. 2002;51(3);81-4.

11. Hwang JM, Ahn K, Kim C, Park KA, Kee C. Ultrasonic biomicroscopic evaluation of cyclodialysis before and after direct cyclopexy. Arch Ophthalmol. 2008;126(9): 1222-5.

12. Mateo-Montoya A, Dreifuss S. Anterior segment optical coherence tomography as a diagnostic tool for cyclodialysis clefts. Arch Ophthalmol. 2009;127(1):109-10.

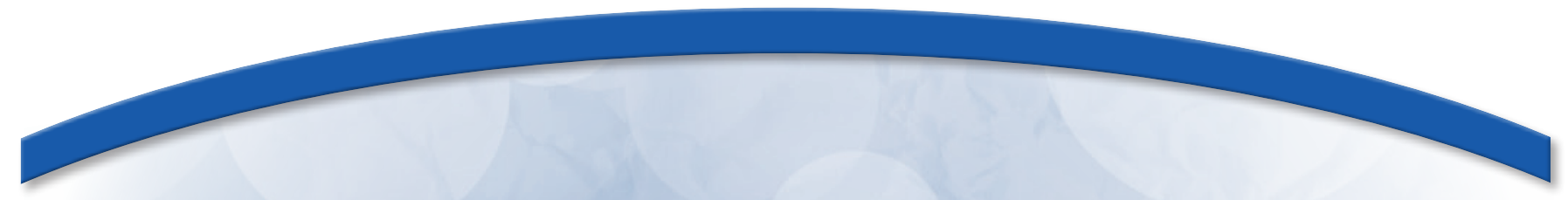

IV Simpósio de Atualização em Oftalmologia

\author{
7 de junho de 2014
}

Hospital Banco de Olhos de Porto Alegre

Porto Alegre - RS

Informações:

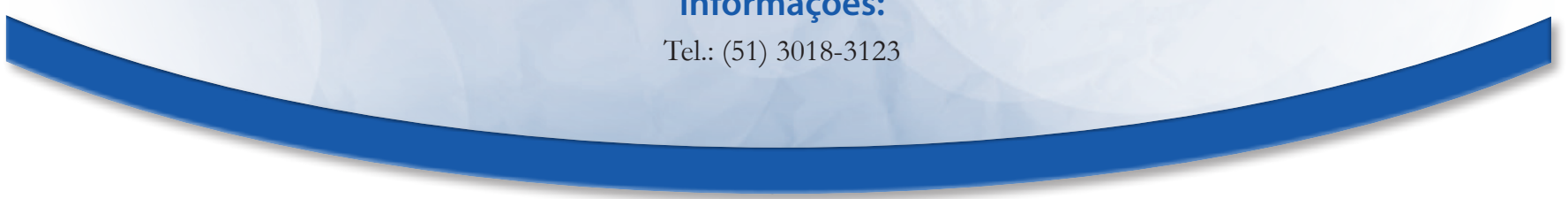

